\title{
Sildenafil up-regulates Kv1.5 mRNA expression in rats with pulmonary hypertension
}

\author{
Lei Hu${ }^{1}$, Lin-hua Tan, Jia-jie Fan ${ }^{1}$, Shan-shan Shi', Li-zhong Du', Long Lin² and Qiang Shu ${ }^{3}$ \\ ${ }^{1}$ Department of Surgical Intensive Care Unit, Children's Hospital, Zhejiang University School of Medicine, Hangzhou, \\ Zhejiang, China. \\ ${ }^{2}$ Department of Pathology, Children's Hospital, Zhejiang University School of Medicine, Hangzhou, Zhejiang, China. \\ ${ }^{3}$ Department of Cardio-thoracic Surgery, Children's Hospital, Zhejiang University School of Medicine, Hangzhou, \\ Zhejiang, China.
}

Accepted 19 October, 2011

\begin{abstract}
The effects of sildenafil on pulmonary vascular remodeling as well as potassium channels (Kv1.5) activity of pulmonary vasculature has not been clearly addressed in pulmonary hypertension secondary to left-to-right shunt. A rat model with pulmonary hypertension secondary to left-to-right shunt was established by performing an abdominal aorta to inferior vena cava fistula. Twenty-seven male Sprague-Dawley (SD) rats were randomly assigned into sham group $(n=9)$, shunt group $(n=9)$ and shunt + sildenafil group $(n=9)$. Rats in shunt + sildenafil group were fed with sildenafil $10 \mathrm{mg} / \mathrm{kg} / \mathrm{day}$ instantly after shunt was established, whereas the rats in the sham group and the shunt group were fed with normal saline of the same volume. Eleven weeks later, the mean pulmonary artery pressure (mPAP), the ratio of right ventricular mass to left ventricular plus septal mass $[R V /(L V+S)]$, the relative medial thickness (RMT) of middle and small pulmonary muscularized arteries, as well as the expression of voltage-gated potassium channel Kv1.5 mRNA in pulmonary vasculature were detected. The rats in shunt group developed pulmonary hypertension as evidenced by significant increase in $\mathrm{mPAP}, \mathrm{RV} /(\mathrm{LV}$ $+S$ ) and RMT (all P < 0.01), meanwhile, the Kv1.5 mRNA expression in pulmonary vasculature decreased $(P<0.01)$. Compared with the shunt group, the rats in shunt + sildenafil group had a significant decrease in $\mathrm{mPAP}, \mathrm{RV} /(\mathrm{LV}+\mathrm{S})$ and $\mathrm{RMT}$ and a significant increase in the expression of Kv1.5 mRNA (all $P<0.01$ ). Interestingly, there were no statistically significant differences between sham group and shunt + sildenafil group in mPAP, RV/(LV +S), RMT and expression of Kv1.5 mRNA (all $P>0.01$ ). Sildenafil attenuates pulmonary vascular remodeling and up-regulates Kv1.5 mRNA expression in rats with pulmonary hypertension secondary to left-to-right shunt.
\end{abstract}

Key words: Sildenafil, potassium channel, pulmonary hypertension.

\section{INTRODUCTION}

Pulmonary hypertension $(\mathrm{PH})$ secondary to left-to-right shunt is a significant complication in children with congenital heart disease (CHD) (Rashid and Ivy, 2005). The pathomorphological changes include pulmonary vasoconstriction, vascular remodeling and ventricular hypertrophy (Lam et al., 2005; Smerling et al., 2005;

*Corresponding author. E-mail: chtlh@zju.edu.cn. Tel: +86 57187061007/60321. Fax: +86 571-87033296.
Mandegar et al., 2004). Studies have shown that the expression and the activity of potassium channels in pulmonary vasculature is closely related to $\mathrm{PH}$ and pulmonary vascular remodeling (Burg et al., 2008; Cornfield et al., 2002; Limsuwan et al., 2001; Moudgil et al., 2006; Weir and Olschewski, 2006). Decreased activity of potassium channels leads to cell proliferation, because of the membrane persistent depolarization, promoting $\mathrm{Ca}^{2+}$ influx, increasing cytosolic free $\mathrm{Ca}^{2+}$ concentration ([Ca $\left.{ }^{2+}\right]$ cyt) and inhibiting cells apoptosis (Mandegar et al., 2004; Yuan et al., 1998). Regulation of 
the activity of potassium channel in prevention and treatment of $\mathrm{PH}$ is of great interest in recent years.

Sildenafil is a phosphodiesterase-5 (PDE-5) inhibitor, selectively decreases pulmonary artery pressure (PepkeZaba et al., 2008; Schermuly et al., 2004; Ghofrani et al., 2003; Dweik, 2002). So far, the effects of sildenafil on pulmonary vascular remodeling and its underlying mechanism of regulating potassium channels activity in pulmonary vasculature in $\mathrm{PH}$ secondary to left-to-right shunt has not been clearly addressed. The objectives of this study were to evaluate the effects of sildenafil on pulmonary vascular remodeling, and also to identify the effects of sildenafil on pulmonary vascular Kv1.5 mRNA expression in a rat model with $\mathrm{PH}$ secondary to left-toright shunt by an abdominal aorta to inferior vena cava fistula (IVC).

\section{METHODS}

\section{Study groups}

Twenty-seven adult male Sprague-Dawley (SD) rats were randomly assigned into sham group $(n=9)$, shunt group $(n=9)$ and shunt + sildenafil group $(n=9)$. Rats from the shunt group and the shunt + sildenafil group underwent laparotomy and left-to-right shunt by an abdominal aorta to IVC fistula. Rats randomized to the sham group underwent the identical surgical procedure except aorta to IVC puncture. The rats in shunt + sildenafil group were fed with sildenafil $10 \mathrm{mg} / \mathrm{kg} /$ day instantly after surgery, whereas the rats in the sham group and the shunt group were fed with normal saline of the same volume.

\section{Establishing a left-to-right shunt}

Rats were anesthetized with intraperitoneal pentobarbital (40 $\mathrm{mg} / \mathrm{kg}$ ) and positioned supine on the table. A midline abdominal incision was made. The abdominal aorta above the renal artery bifurcation was identified after careful dissection. The supra-renal portion of the aorta and IVC were exposed at the site where the two vessels share a common fascia. At this site, a 9/0 polypropylene suture was applied on the anterior surface of the aorta. The suprarenal portion of the abdominal aorta was then occluded with a snugger to control bleeding. The aorto-caval shunt was then created with an $18 \mathrm{G}$ angiocatheter inserted in the sutures on the aorta, and then advancing the catheter into the IVC. The sutures were tied upon withdrawal of the catheter. After releasing of the snugger, mixing of arterial and venous blood in the IVC were observed, with distention and pulsation of the IVC. The abdomen was then closed using 4/0 silk sutures after achieving hemostasis. All animals were recovered on a warm bed, and routine care was given to 3 groups of rats until 11 weeks after left-to-right shunt operation in accordance with the 'Guiding Principles in the Care and Use of Animals'.

\section{Hemodynamic measurement}

Eleven weeks after the shunt operation, all rats were anesthetized with intraperitoneal pentobarbital $(40 \mathrm{mg} / \mathrm{kg}$ ) and positioned supine on the table. A midline abdominal incision was again made and the IVC and aorta were visualized. The persistence of the surgically created aorto-caval shunt was ensured visually. Then, the mean pulmonary artery pressure (mPAP) was measured with a right ventricular catheter as follows: A catheter (Hydrocath $20 \mathrm{G} / 1.1$, OHMEDA, UK) was elongated in hot water $\left(80^{\circ} \mathrm{C}\right)$, and the diameter of the catheter was about $1.0 \mathrm{~mm}$. A small incision was made in the neck, $0.5 \mathrm{~cm}$ to the right of the midclavicular line. The right external jugular vein was isolated. Two $2 / 0$ silk ligatures were placed around the vein and the distal end was ligated. A small transverse cut was made proximally in the vein through which the Spring-Wire Guide (OD $0.64 \mathrm{~mm}$ ) and catheter were passed. The catheter, pre-flushed with heparinized saline and connected to a pressure transducer (Edwards Lifesciences PX260) and a monitor (IntelliVue MP50, Philips, Germany) was inserted into the external jugular vein, and advanced into the right ventricle about $3 \mathrm{~cm}$. The catheter position was confirmed by the typical right ventricular pressure tracing seen in the monitor. Then, the catheter was further inserted about $0.5 \mathrm{~cm}$ into pulmonary artery. The values of mPAP of all the rats were recorded, respectively.

\section{Pathological examination}

After the values of mPAP were measured, rats were sacrificed with over-dose of intraperitoneal pentobarbital. Thoracic cavity was opened and the heart and the bilateral lungs were exposed. The heart was taken out of the thoracic cavity. Heart tissue was separated as right ventricle (RV) and left ventricle plus ventricular septum $(L V+S)$, the mass ratio of the weight of $R V$ to $(L V+S)$ was calculated $[R V /(L V+S)]$. Right lung was quickly removed and then frozen in liquid nitrogen, stored at $-80^{\circ} \mathrm{C}$ for further use. Left lung was removed for pathological examination.

Left lung tissue was fixed in $4 \%$ paraformaldehyde for $72 \mathrm{~h}$ and was embedded in paraffin. The lung tissue was stained with Hart's, and then Van Gieson. The morphologic alterations of the pulmonary arteries were observed under optical microscope by a pathologist assigned to study the groups. The relative medial wall thickness (RMT) of middle and small pulmonary arteries (diameter is about 50 to $200 \mathrm{um}$ ) was calculated by CMIAS graphic processing system. Atleast 10 middle and small pulmonary arteries' RMT were measured and then a mean value was obtained.

\section{Detection of Kv1.5 mRNA expression level}

Right lung tissue (100 mg) was extracted and immediately frozen in liquid nitrogen and grounded to powder with a prechilled mortar and pestle. The powder was then homogenized in $1.5 \mathrm{ml}$ RNAiso Plus (TaKaRa, Japan). Following the manufacturer's instructions, total RNA was extracted and reverse-transcripted, then dissolved in 50 $\mathrm{ml}$ diethyl pyrocarbonate-treated water and stored at $-70^{\circ} \mathrm{C}$. Realtime polymerase chain reaction (RT-PCR) was performed according to the standard protocols (7500 Real-time PCR System, One Step SYBR ${ }^{\circledR}$ PrimeScript ${ }^{\mathrm{TM}}$ RT-PCR Kit, TaKaRa, Japan). Reverse transcription was conducted under the conditions of $37^{\circ} \mathrm{C}$ for 15 min, followed by another $5 \mathrm{~s}$ at $85^{\circ} \mathrm{C}$. The amplification scheme consisted of $5 \mathrm{~min}$ at $94^{\circ} \mathrm{C}$, followed by 35 cycles of $15 \mathrm{~s}$ at $94^{\circ} \mathrm{C}$, $25 \mathrm{~s}$ at $55^{\circ} \mathrm{C}, 30 \mathrm{~s}$ at $72^{\circ} \mathrm{C}$, and then an extension of $35 \mathrm{~s}$ at $72^{\circ} \mathrm{C}$. PCR primers employed were shown as follows:

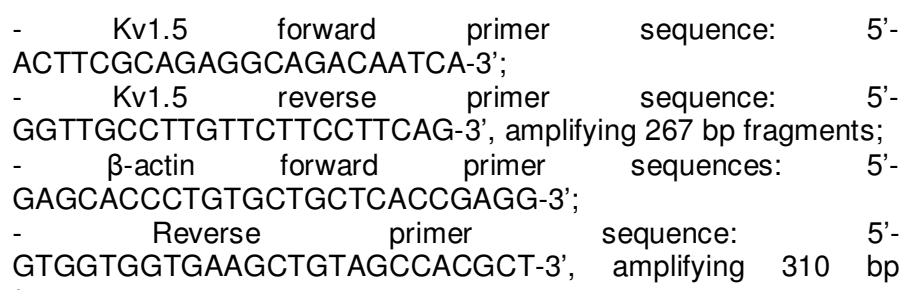
fragments;

The relative Kv1.5 mRNA expression level was standardized by $\beta$ - 
Table 1. Comparison of the hemodynamic and pathological changes in 3 study groups.

\begin{tabular}{llccc}
\hline Study group & $\mathbf{n}$ & $\mathbf{m P A P}(\mathbf{m m H g})$ & $\mathbf{R V} /(\mathbf{L V + S})$ & RMT (\%) \\
\hline Sham & 9 & $14.6 \pm 0.2$ & $0.27 \pm 0.01$ & $13.29 \pm 0.29$ \\
Shunt & 9 & $21.7 \pm 0.4^{\dagger}$ & $0.33 \pm 0.01^{\dagger}$ & $27.12 \pm 0.97^{\dagger}$ \\
Shunt + sildenafil & 9 & $15.6 \pm 0.3^{*}$ & $0.28 \pm 0.01^{*}$ & $13.53 \pm 0.38^{\star}$ \\
\hline
\end{tabular}

mPAP = mean pulmonary arterial pressure; $R V /(L V+S)=$ the mass ratio of right ventricular to left ventricular plus septum; RMT = relative medial thickness of middle and small pulmonary muscularized arteries. ${ }^{\dagger} P<0.01$, compared between the Shunt + sildenafil group and the sham group; ${ }^{*} P<0.01$, compared between the Shunt + sildenafil group and the shunt group.
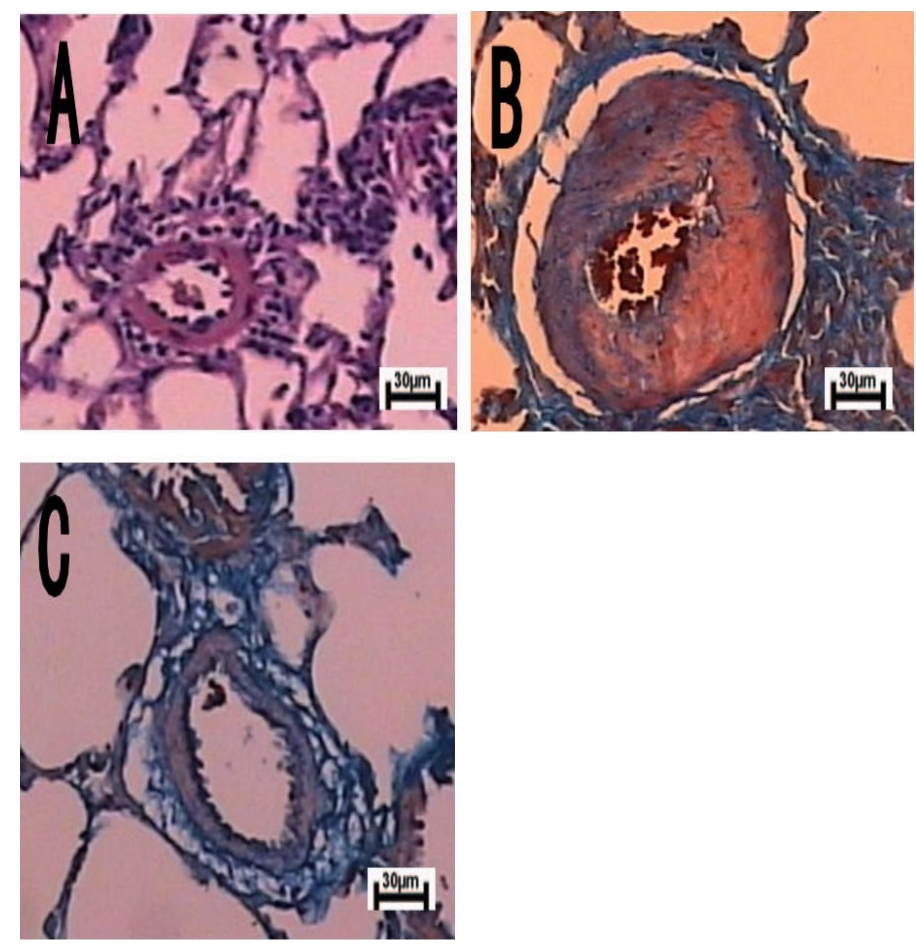

Figure 1. The morphologic alterations of the pulmonary arteries were observed through the relative medial wall thickness (RMT) of middle and small pulmonary arteries. Pathology of pulmonary vasculature in sham group $(A)$; Pathology pulmonary vasculature in shunt group (B); pathology pulmonary vasculature in shunt + sildenafil group $(\mathrm{C})$.

actin. The difference of a cycle threshold $(\mathrm{Ct})$ of the sample and $\beta$ $\operatorname{actin}[\Delta \mathrm{Ct}=\mathrm{Ct}(\mathrm{Kv} 1.5)-\mathrm{Ct}(\beta$-actin) $]$ was expressed as the relative contents of mRNA in the sample.

\section{Statistical analysis}

All data were presented as mean \pm SD. Statistical analyses were performed using one-way ANOVA t-test using SPSS 10.0 software. $A$ value of $P<0.05$ was considered statistically significant.

\section{Ethical issues}

This study was approved by the research and ethics committee of Children's Hospital, Zhejiang University School of Medicine, Hangzhou, Zhejiang, China.

\section{RESULTS}

\section{Hemodynamic parameters}

Eleven weeks after the shunt operation, the rats in the shunt group had a significant increase in mPAP than in the sham group $(21.7 \pm 0.4 \mathrm{mmHg}$ versus $14.6 \pm 0.2$ $\mathrm{mmHg}, \mathrm{P}<0.01)$, whereas the rats in the shunt + sildenafil group had a significant decrease in mPAP than in the shunt group $(15.6 \pm 0.3 \mathrm{mmHg}$ versus $21.7 \pm 0.4$ $\mathrm{mmHg}, \mathrm{P}<0.01)$. On the other hand, there were no statistically significant differences in MPAP between the shunt + sildenafil group and the sham group (15.6 \pm 0.3 $\mathrm{mmHg}$ versus $14.6 \pm 0.2 \mathrm{mmHg}, \mathrm{P}>0.05$ ) (Table 1 ).

\section{Pathological observations}

Eleven weeks after the shunt operation, the rats in the shunt group had a significant increase in mass ratio of $\mathrm{RV} /(\mathrm{LV}+\mathrm{S})(0.33 \pm 0.01$ versus $0.27 \pm 0.01, \mathrm{P}<0.01)$, and a significant increase in RMT of middle and small pulmonary muscularized arteries $(27.12 \pm 0.97$ versus $13.29 \pm 0.29, P<0.01)$ than in the sham group, whereas the rats in the shunt + sildenafil group had a significant decrease in mass ratio of $R V /(L V+S)(0.28 \pm 0.01$ versus $0.33 \pm 0.01, P<0.01$ ), and a significant decrease in RMT of middle and small pulmonary muscularized arteries $(13.53 \pm 0.38$ versus $27.12 \pm 0.97, P<0.01)$ than in the shunt group. On the other hand, there were no statistically significant differences in the mass ratio of $R V /(L V+S)(0.28 \pm 0.01$ versus $0.27 \pm 0.01, P>0.05)$ and the RMT of middle and small pulmonary muscularized arteries (13.53 \pm 0.38 versus $13.29 \pm 0.29, \mathrm{P}>0.05)$ between the shunt + sildenafil group and the sham group (Table 1 and Figure 1).

\section{Kv1.5 mRNA expression levels}

The rats in the shunt group had a decreased Kv1.5 mRNA expression in pulmonary vasculature $(9.83 \pm 0.49$ versus $3.02 \pm 0.31, P<0.01)$ than the sham group. The levels of Kv1.5 mRNA expression were significantly upregulated in the shunt + sildenafil group than in the shunt group (3.04 \pm 0.31 versus $9.83 \pm 0.49, P<0.01)$. There 
Table 2. Comparison of pulmonary vascular Kv1.5 mRNA expression in 3 study groups.

\begin{tabular}{lll}
\hline Study group & $\mathbf{n}$ & $\boldsymbol{\Delta} \mathbf{C t}$ \\
\hline Sham & 9 & $3.02 \pm 0.31$ \\
Shunt & 9 & $9.83 \pm 0.49^{\dagger}$ \\
Shunt + sildenafil & 9 & $3.04 \pm 0.31^{\star}$ \\
\hline
\end{tabular}

$\Delta \mathrm{Ct}$ : The difference of a cycle threshold $(\mathrm{Ct})$ of sample and $\beta$-actin; ${ }^{\dagger} \mathrm{P}<0.01$, compared between the shunt + sildenafil group and the sham group; ${ }^{*} P<0.01$, compared between the shunt + sildenafil group and the shunt group.

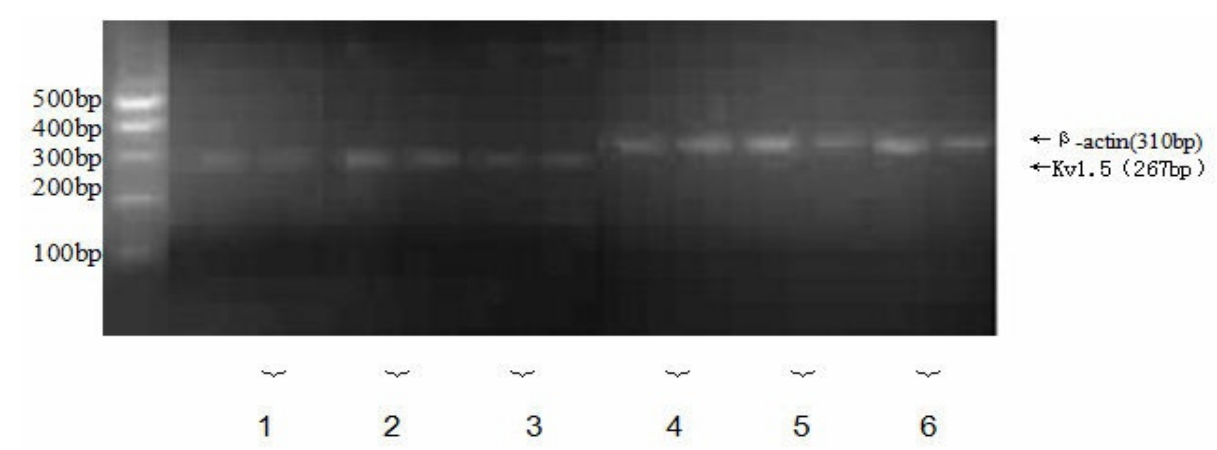

Figure 2. Pulmonary vascular Kv1.5 mRNA expression in electrophoresis of the 3 study groups. The relative Kv1.5 mRNA expression level was standardized by $\beta$-actin. The difference of a cycle threshold (Ct) of the sample and $\beta$-actin $[\Delta \mathrm{Ct}=\mathrm{Ct}(\mathrm{Kv1.5})-\mathrm{Ct}(\beta-$ actin)] was expressed as the relative contents of mRNA in the sample. (1) Shunt group, (2) sham group, (3) shunt + sildenafil group, (4) $\beta$-actin in shunt group, (5) $\beta$-actin in sham group and (6) $\beta$-actin in shunt + sildenafil group.

was no statistically significant difference of the Kv1.5 mRNA expression levels between the sham group and the shunt + sildenafil group (3.02 \pm 0.31 versus $3.04 \pm$ $0.31, \mathrm{P}>0.05$ ) (Table 2 and Figure 2).

\section{DISCUSSION}

Compared with other models such as aortopulmonary shunt that is somewhat similar to the left-to-right shunt, the model of abdominal aorta to inferior vena cava fistula was proved to mirror the pathophysiology of children suffering from congenital heart disease with left-to-right shunt and pulmonary hypertension, as well as a lower cost, relatively simple surgical procedure and reproducible experiment (Ocampo et al., 2003; Garcia and Diebold, 1990). In our study, the rats in shunt group had a significant increase in mPAP, a significant increase in mass ratio of $\mathrm{RV} /(\mathrm{LV}+\mathrm{S})$ and a significant increase in RMT of middle and small pulmonary muscularized arteries 11 weeks after the creation of aorto-caval shunt, suggesting that left-to-right shunt in SD rats resulted in increased pulmonary blood flow, pulmonary hypertension, right ventricular hypertrophy and vascular remo- deling in small and medium sized pulmonary arteries. Our data also showed that sildenafil significantly decreased mPAP, mass ratio of $R V /(L V+S)$ and RMT of middle and small pulmonary muscularized arteries in rats with pulmonary hypertension secondary to left-to-right shunt. Furthermore, there were no statistically significant differences in mPAP, mass ratio of $R V /(L V+S)$ and the RMT of middle and small pulmonary muscularized arteries between the rats in shunt + sildenafil group and those rats without left-to-right shunt. These findings suggest that the long-term sildenafil can significantly reduce pulmonary artery pressure and attenuate the pulmonary vascular remodeling in rats with $\mathrm{PH}$ second to left-to-right shunt.

There are several potential mechanisms underlying these aforementioned effects of sildenafil. First of all, sildenafil selectively inhibits PDE-5, increases intracellular concentration of cGMP, activates protein kinase $\mathrm{G}(\mathrm{PKG})$ and increases the activity of $\mathrm{Ca}^{2+}$-ATP enzyme. Sildenafil leads to the opening of potassium channel of myosin and results in cell membrane hyperpolarization, decreasing cytosolic free $\mathrm{Ca}^{2+}$ concentration ([ $\left.\mathrm{Ca}^{2+}\right]$ cyt) and dilating the pulmonary vessel. Sildenafil decreases the activity of myosin light chain kinase and reduces 
the speed of myosin phosphorylation, so that the smooth muscle cell is contractility reduced, and pulmonary vascular smooth muscle can dilate (Ignarro, 1990). Secondly, sildenafil reduces pulmonary arterial pressure, decreasing the shearing forces on endothelial cells and the mRNA expression of vascular endothelial growth factor (VEGF) (Chan and Loscalzo, 2008; Rondelet et al., 2004). Thirdly, sildenafil increases intracellular concentration of CAMP and influences the activity of adenylate cyclase, activates protein kinase A (PKA), inhibits growth factors and reduces pulmonary vascular remodeling (Osinski et al., 2001).

Potassium channels may play an important role in the process of $\mathrm{PH}$, including the pulmonary vasoconstriction and pulmonary vascular remodeling. There are several types of potassium channel on pulmonary vasculature: (1) voltage-gated potassium channel (Kv); (2) calciumsensitive potassium channel $(\mathrm{KCa})$; (3) $\mathrm{PH}$-sensitive potassium channel (TASK); (4) two-pore domain acidsensitive potassium channel $\left(\mathrm{K}_{2} \mathrm{P}\right)$. Up to now, most of the studies described the influence of Kv activity in hypoxic pulmonary hypertension (Coppock et al., 2001; Archer et al., 2004; Platoshyn et al., 2001), but few studies have published, focusing on the Kv activity in $\mathrm{PH}$ secondary to left-to-right shunt. Our study have identified that the levels of Kv1.5 mRNA expression was downregulated in pulmonary vasculature of rats with $\mathrm{PH}$ secondary to left-to-right shunt associated with an increase in mPAP and pulmonary remodeling. In addition, we found that sildenafil significantly up-regulated Kv1.5 mRNA expression levels, associating with reduced pulmonary artery pressure and pulmonary vascular remodeling simultaneously. There were no statistically significant differences of the levels of Kv1.5 mRNA expression between the sham group and the shunt + sildenafil group. These give us a theoretical principle of the use of $\mathrm{Kv}$ channels inhibitor in treating $\mathrm{PH}$ secondary to left-to-right shunt.

$\mathrm{PH}$ leads to the increased produce of ET-1 and decreased synthesis of nitric oxide (NO) in endothelial cell (Hampl and Herget, 2000). ET-1 actives protein kinase $C$ (PKC), inhibits the activity of Kv1.5 channels, and then down-regulates the levels of Kv1.5 mRNA expression (Boland and Jackson, 1999). The decreased NO synthesis inhibits soluble guanylate cyclase (sGC), decreases cGMP, inhibits PKG and then down-regulates the levels of Kv1.5 mRNA expression (Krick et al., 2002; Potet et al., 2001; Pozeg et al., 2003). The activity of Kv channels regulates cellular resting membrane potential $(\mathrm{Em})$. Inhibition of $\mathrm{Kv}$ channels activity results in membrane depolarization (Burg et al., 2008). The downregulation of Kv1.5 mRNA expression affects cell resting membrane potential and cell membrane depolarization, which opens $\mathrm{L}-\mathrm{Ca}^{2+}$ channels, increases $\left[\mathrm{Ca}^{2+}\right]$ cyt, activates actin-myoglobulin retractor, resulting in pulmonary vasonstriction and pulmonary vascular remodeling. Sildenafil effectively reduced pulmonary arterial pressure, reduced the shear stress on endothelial cell and the injury in pulmonary vasculature, and avoid the increased ET-1 synthesis and reduced NO synthesis in $\mathrm{PH}$ with left-to-right shunt.

\section{Limitation}

This study showed that there was a downregulation in Kv1.5 expression in rats that underwent left-to-right shunt. The treatment with sildenafil inhibited the enhancement of pulmonary artery pressure and thickness as well as right ventricular hypertrophy. Furthermore, sildenafil treatment inhibited the downregulation of Kv1.5 channels. However, it should be noted that, it was better to test the quantification of mRNA of Kv1.5 channels in isolated pulmonary arteries instead of in whole right lung tissue used in our study.

\section{Conclusion}

Long-term sildenafil reduced pulmonary artery pressure effectively and up-regulated the expression of Kv1.5 mRNA in pulmonary vasculature, thereby attenuating the pulmonary vascular remodeling in rats with $\mathrm{PH}$ secondary to left-to-right shunt. These findings provide a theoretical basis for the use of $\mathrm{Kv}$ channel inhibitors in treating patients with congenital heart disease and $\mathrm{PH}$.

\section{ACKNOWLEDGEMENTS}

The author is grateful to Dr. Minglei Yang for teaching us how to do aorto-caval shunt in rats. The author is also grateful to Dr. Mudit Mathur from Loma Linda University, USA for writing and editing assistance.

\section{REFERENCES}

Archer SL, Wu XC, Thébaud B, Nsair A, Bonnet S, Tyrrell B, McMurtry MS, Hashimoto K, Harry G, Michelakis ED (2004). Preferential expression and function of voltage-gated, $\mathrm{O}_{2}$-sensitive $\mathrm{K}^{+}$channels in resistance pulmonary arteries explains regional heterogeneity in hypoxic pulmonary vasoconstriction: ionic diversity in smooth muscle cells. Circ. Res., 95(3): 308-318.

Boland LM, Jackson KA (1999). Protein kinase C inhibits Kv1.1 potassium channel function. Am. J. Physiol., 277(1Pt 1): C100-110.

Burg ED, Remillard CV, Yuan JX-J (2008). Potassium channels in the regulation of pulmonary artery smooth muscle cell proliferation and apoptosis: pharmacotherapeutic implications. Br. J. Pharmacol., 153(1): S99-111.

Chan SY, Loscalzo J (2008). Pathogenic mechanisms of pulmonary arterial hypertension. J. Mol. Cell Cardiol., 44(1):14-30.

Coppock EA, Martens JR, Tamkun MM (2001). Molecular basis of hypoxia- induced pulmonary vasoconstriction: role of voltage-gated $\mathrm{K}^{+}$channels. Am. J. Physiol., 281(1): L1-12.

Cornfield DN, Resnik ER, Herron JM, Reinhartz O, Fineman JR (2002). Pulmonary vascular $\mathrm{K}^{+}$channel expression and vasoreactivity in a model of congenital heart disease. Am. J. Physiol. Lung Cell Mol. Physiol., 283(6): L1210-1219.

Dweik RA (2002). Pulmonary hypertension and the search for the 
selective pulmonary vasodilator. Lancet, 360(9337): 886-887.

Garcia R, Diebold S (1990. Simple, rapid and effective method of producing aortocaval shunts in the rat. Cardiovasc. Res., 24(5): 430432.

Ghofrani HA, Rose F, Schermuly RT, Olschewski H, Wiedemann R, Kreckel A, Weissmann N, Ghofrani S, Enke B, Seeger W, Grimminger $F$ (2003). Oral sildenafil as long-term adjunct therapy to inhaled iloprost in severe pulmonary arterial hypertension. J. Am. Coll. Cardiol., 42(1): 158-164.

Hampl V, Herget J (2000). Role of Nitric Oxide in the pathogenesis of chronic pulmonary hypertension. Physiol. Rev., 80(4):1337-1372.

Ignarro LJ (1990). Biosynthesis and metabolism of endothelium derived nitric oxide. Annu. Rev. Pharmacol. Toxicol., 30: 535-560.

Krick S, Platoshyn O, Sweeney M, McDaniel SS, Zhang S, Rubin LJ, Yuan JX (2002). Nitric oxide induces apoptosis by activating $\mathrm{K}^{+}$ channels in pulmonary vascular smooth muscle cells. Am. J. Physiol. Heart Circ. Physiol., 282(1): H184-193.

Lam CF, Peterson TE, Croatt AJ, Nath KA, Katusic ZS (2005). Functional adaptation and remodeling of pulmonary artery in flowinduced pulmonary hypertension. Am. J. Physiol. Heart Circ. Physiol., 289(6): H2334-2341.

Limsuwan A, Platoshyn O, Yu Y, Rubin LJ, Rothman A, Yuan JX (2001). Inhibition of $\mathrm{k}^{+}$Channel activity in human pulmonary artery smooth muscle cells by serum from patients with pulmonary hypertension secondary to congenital heart disease. Pediatr. Res., 50(1): 23-28.

Mandegar M, Fung YC, Huang W, Remillard CV, Rubin LJ, Yuan JX (2004). Cellular and molecular mechanisms of pulmonary vascular remodeling: role in the development of pulmonary hypertension. Microvasc. Res., 68(2): 75-103.

Moudgil R, Michelakis ED, Archer SL (2006). The role of $k^{+}$channels in determinin pulmonary vascular tone, oxygen sensing, cell proliferation, and apoptosis: implications in hypoxic pulmonary vasoconstriction and pulmonary arterial hypertension. Microcirculation, 13(8): 615-632.

Ocampo C, Ingram P, Ilbawi M, Arcilla R, Gupta M (2003). Revisiting the surgical creation of volume load by aorto-caval shunt in rats. Mol. Cell Biochem., 251(1-2): 139-143.

Osinski MT, Rauch BH, Schror K (2001). Antimitogenic actions of organic nitrates are potentiated by sildenafiland mediated via activation of protein kinase A. Mol. Pharmacol., 59(5): 1044-1050.
Platoshyn O, Yu Y, Golovina VA, McDaniel SS, Krick S, Li L, Wang JY, Rubin LJ, Yuan JX (2001). Chronic hypoxia decreases Kv channel expression and function in pulmonary artery myocytes. Am. J. Physiol. Lung Cell Mol. Physiol., 280(4): L801-812.

Potet F, Scott JD, Mohammad-Panah R, Escande D, Baró I (2001). AK

AP proteins anchor cAMP- dependent protein kinase to KvLQT1/lsK channel complex. Am. J. Physiol. Heart Circ. Physiol., 280(5): H20382045.

Pozeg ZI, Michelakis ED, McMurtry MS, Thébaud B, Wu XC, Dyck JR, Hashimoto K, Wang S, Moudgil R, Harry G, Sultanian R, Koshal A, Archer SL (2003). In vivo gene transfer of the $\mathrm{O}_{2}$-sensitive potassium channel Kv1.5 reduces pulmonary hypertension and restores hypoxic pulmonary vasoconstriction in chronically hypoxic rats. Circulation, 107(15): 2037-2044.

Pepke-Zaba J, Gilbert C, Collings L, Brown MC (2008). Sildenafil improves health-related quality of life in patients with pulmonary arterial hypertension. Chest, 133(1): 183-189.

Rashid A, Ivy D (2005). Severe paediatric pulmonary hypertension: New management strategies., 90(1): 92-98.

Rondelet B, Kerbaul F, Van Beneden R, Motte S, Fesler P, Hubloue I, Remmelink M, Brimioulle S, Salmon I, Ketelslegers JM, Naeije R (2004). Signaling molecules in overcirculation-induced pulmonary hypertension in piglets: effects of sildenafil therapy. Cicrulation, 110(15): 2220-2225.

Schermuly RT, Kreisselmeier KP, Ghofrani HA, Yilmaz H, Butrous G, Ermert L, Ermert M, Weissmann N, Rose F, Guenther A, Walmrath D, Seeger W, Grimminger F (2004). Chronic Sildenafil treatment inhibits monocretaline-induced pulmonary hypertension in rats. Am. J. Respir. Crit. Care Med., 169(1): 39-45.

Smerling AJ, Schleien CL, Barst RJ (2005). Pulmonary Hypertension. In: Nichols DG, Ungerleider RM, Spevall PJ (eds) Critical heart disease in infants and children. Philadelphia: Mosby, pp. 885-897.

Weir EK, Olschewski A (2006). Role of ion channels in acute and chronic responses of the pulmonary vasculature to hypoxia. Cardiovasc. Res., 71(4): 630-641.

Yuan XJ, Wang J, Juhaszova M, Golovina VA, Rubin LJ (1998). Molecular basis and function of voltage-gated $\mathrm{K}^{+}$channels in pulmonary arterial smooth muscle cells. Am. J. Physiol., 274(4 Pt 1): L621- 635. 